\title{
GGA1 Is Expressed in the Human Brain and Affects the Generation of Amyloid $\beta$-Peptide
}

\author{
Tina Wahle, ${ }^{1}$ Dietmar R. Thal, ${ }^{2}$ Magdalena Sastre, ${ }^{1}$ Andrea Rentmeister, ${ }^{3}$ Nenad Bogdanovic, ${ }^{4}$ Michael Famulok, ${ }^{3}$ \\ Michael T. Heneka, ${ }^{1}$ and Jochen Walter ${ }^{1}$ \\ ${ }^{1}$ Department of Neurology, ${ }^{2}$ Institute of Neuropathology, and ${ }^{3}$ Kekulé-Institute for Organic Chemistry and Biochemistry, University of Bonn, 53127 Bonn, \\ Germany, and ${ }^{4}$ Karolinska Institute, Neurotec, Geriatric Department and Huddinge Brain Bank Klinisk Forskingscentrum, 14186 Stockholm, Sweden
}

The $\beta$-amyloid peptide $(\mathrm{A} \beta)$ is a major component of Alzheimer disease $(\mathrm{AD})$-associated senile plaques and is generated by sequential cleavage of the $\beta$-amyloid precursor protein (APP) by $\beta$-secretase (BACE1) and $\gamma$-secretase. BACE1 cleaves APP at the N terminus of the $\mathrm{A} \beta$ domain, generating a membrane-bound C-terminal fragment (CTF- $\beta$ ) that can be subsequently cleaved by $\gamma$-secretase within the transmembrane domain to release $\mathrm{A} \beta$. Because BACE1 initiates $\mathrm{A} \beta$ generation, it represents a potential target molecule to interfere with $\mathrm{A} \beta$ production in therapeutic strategies for AD. BACE1 interacts with Golgi-localized, $\gamma$-ear-containing, ADP ribosylation factor-binding (GGA) proteins that are involved in the subcellular trafficking of BACE1. Here, we show that GGA1 is preferentially expressed in neurons of the human brain. GGA1 was also detected in activated microglia surrounding amyloid plaques in AD brains. Functional analyses with cultured cells demonstrate that GGA1 is implicated in the proteolytic processing of APP. Overexpression of GGA1 or a dominant-negative variant reduced cleavage of APP by BACE1 as indicated by a decrease in CTF- $\beta$ generation. Importantly, overexpression of GGA1 reduced, whereas RNAi-mediated suppression of GGA1 increased the secretion of $\mathrm{A} \beta$. The modulation of APP processing by GGA1 is independent of a direct interaction of both proteins. Because total cellular activity of BACE1 was not affected by GGA1 expression, our data indicate that changes in the subcellular trafficking of BACE1 or other GGA1-dependent proteins contribute to changes in APP processing and A $\beta$ generation. Thus, GGA proteins might be involved in the pathogenesis of AD.

Key words: APP; secretase; BACE; trafficking; processing; endosomes

\section{Introduction}

Accumulation of the amyloid $\beta$-peptide $(\mathrm{A} \beta)$ is an invariant feature of Alzheimer's disease (AD), and increasing evidence suggests that this peptide plays an important role in $\mathrm{AD}$ pathogenesis (Hardy and Selkoe, 2002; Aguzzi and Haass, 2003). A $\beta$ derives from the $\beta$-amyloid precursor protein (APP) by proteolytic processing involving sequential cleavages by $\beta$-secretase and $\gamma$-secretase (Selkoe, 2001; Walter et al., 2001a; Annaert and de Strooper, 2002). $\beta$-secretase was identified as the aspartyl protease $\beta$-site APP cleaving enzyme-1 (BACE1) that cleaves APP at the $\mathrm{N}$ terminus of the A $\beta$ domain (Hussain et al., 1999; Sinha et al., 1999; Yan et al., 1999; Haniu et al., 2000; Lin et al., 2000). This cleavage results in the secretion of the APP ectodomain (APPs- $\beta$ ) and the generation of a membrane bound C-terminal fragment $(\mathrm{CTF}-\beta)$ that can be subsequently cleaved by $\gamma$-secretase to release $\mathrm{A} \beta$.

Because BACE1 initiates $A \beta$ generation and represents a po-

Received Dec. 23, 2005; revised 0ct. 31, 2006; accepted Nov. 3, 2006.

This work was supported by grants from the Deutsche Forschungsgemeinschaft and the Herbert-ReeckFoundation (to J.W.). We thank Drs. M. S. Robinson and J. Bonifacino for GGA CDNA. We also thank Dr. C. Haass for antibodies and helpful discussions and Drs. B. Hyman and C. von Arnim for sharing unpublished data.

Correspondence should be addressed to Dr. Jochen Walter, Department of Neurology, University of Bonn, Sigmund-Freud-Strasse 25, 53127 Bonn, Germany. E-mail: Jochen.Walter@ukb.uni-bonn.de.

M. T. Heneka's present address: Department of Neurology, University of Munster, 48149 Munster, Germany. D0I:10.1523/JNEUROSCI.1982-06.2006

Copyright $\odot 2006$ Society for Neuroscience $\quad$ 0270-6474/06/2612838-09\$15.00/0 tential target to lower $\mathrm{A} \beta$ levels in the brain, it is important to understand the molecular mechanisms that regulate its cellular metabolism and activity. During transport through the secretory pathway, BACE1 undergoes maturation by complex $\mathrm{N}$-glycosylation and proteolytic removal of the pro-peptide (Capell et al., 2000; Creemers et al., 2000). Mature BACE1 is then transported to the cell surface, from which it can be reinternalized into endosomal compartments (Huse et al., 2000; Walter et al., 2001b). Consistent with the subcellular localization of BACE1, $\beta$-secretase cleavage of APP has been identified in the trans-Golgi network (TGN) and endosomal compartments as well as at the plasma membrane (Vassar and Citron, 2000; Walter et al., 2001a). The subcellular transport of BACE1 is regulated by phosphorylation of its cytoplasmic domain by casein kinase-1 (Walter et al., 2001b; Pastorino et al., 2002). Phosphorylation of BACE1 also affects the interaction with Golgi-localized, $\gamma$-earcontaining, ADP ribosylation factor-binding (GGA) proteins that bind to a characteristic motif within the cytoplasmic domain (von Arnim et al., 2004; He et al., 2002; Shiba et al., 2004; He et al., 2003).

GGA proteins are monomeric adaptor proteins that mediate transport of cargo proteins between the TGN and endosomes (Dell'Angelica et al., 2000; Hirst et al., 2000; Doray et al., 2002). The proteins contain distinct domains that serve several functions in protein sorting and vesicle targeting. Although the $\mathrm{N}$-terminal Vps, Hrs, and STAM (VHS) domain binds to DXXLL 

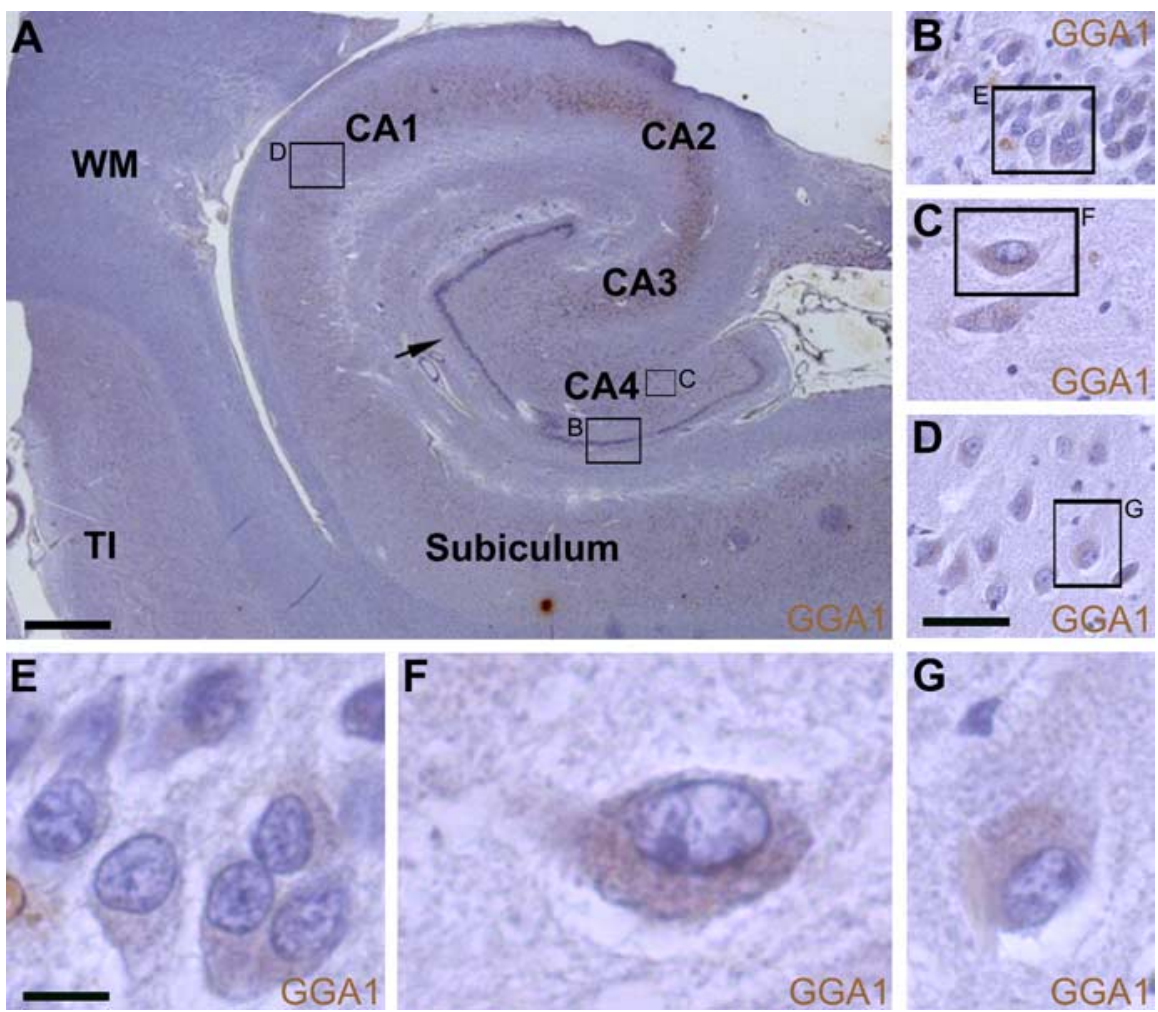

Figure 1. Expression of GGA1 in neuronal cells in $A D$ brain. $\boldsymbol{A}-\mathbf{G}$, Detection of $G G A 1$ in human $A D$ brain was performed as described in the Materials and Methods. The hippocampal formation exhibits a distinct diffuse neuropil staining for GGA1 of the neuropil of the pyramidal cell layer of the subiculum, the Ammon's horn sectors CA1-CA3 as well as in the molecular layer of the dentate gyrus (arrows). The presubicular region, the temporal isocortex (TI) and the CA4 region exhibit lower levels of GGA1. The white matter did not exhibit a significant GGA1 staining. The hippocampal formation of an AD brain exhibits a pattern similar to normal human brain (see also supplemental Fig. 2, available at www.jneurosci.org as supplemental material). Neuropil staining is pronounced in the hippocampal subfields CA1-CA3, the subiculum, and the molecular layer of the fascia dentata (arrows). The neuropil of the TI was less densely stained. The white matter (WM) did not exhibit GGA1. Neurons of the dentate gyrus displayed a faint cytoplasmic staining $(\boldsymbol{B}, \boldsymbol{E})$. CA4 dentate hilar cells contained large amounts of GGA1-positive, cytoplasmic material $(\boldsymbol{C}, \boldsymbol{F})$ and CA1 pyramidal cells showed a small amount of cytoplasmic GGA1 material (D, G). Scale bars: $\boldsymbol{A}, 800 \mu \mathrm{m}$; (in $\boldsymbol{D}) \boldsymbol{B}-\boldsymbol{D}, 70 \mu \mathrm{m}$; (in $\boldsymbol{E}) \boldsymbol{E}-\boldsymbol{G}, 3 \mu \mathrm{m}$.

motifs in cytoplasmic domains of cargo proteins, the GGA and Tom (GAT) domain and a variable hinge region bind to ADPribosylation factors (ARFs) and clathrin, respectively. The $\gamma$-adaptin ear (GAE) domain can interact with additional proteins (Bonifacino, 2004). Although the function of GGAs in cultured peripheral cells is well established, their roles in the nervous system or an involvement in neurodegenerative diseases is not known.

Here, we demonstrate that GGA1 is preferentially expressed in neuronal cells in the human brain. GGA1 was also detected in activated microglial cells in AD brains. By analyzing the functional role of GGA 1 in cultured cells with endogenous $\beta$-secretase activity, we found that GGA1 alters the proteolytic processing of APP and the secretion of APPs and A $\beta$. Together, our data demonstrate that GGA1 is functionally involved in $A \beta$ generation, suggesting a role of this protein in $\mathrm{AD}$ pathogenesis.

\section{Materials and Methods}

Reagents and human brain tissue. The monoclonal antibody against c-myc was purchased from LGC Promochem (Teddington, UK). Antibody 5313 recognizing the N-terminal domain of APP (Walter et al., 2001b) and antibody 7520 against the cytoplasmic domain of BACE1 (Walter et al., 2001b) were generously provided by Dr. C. Haass (University of Munich, Germany). Polyclonal antibodies 2964 against A $\beta$ and antibody 140 against the C-terminal domain of APP were raised by in-

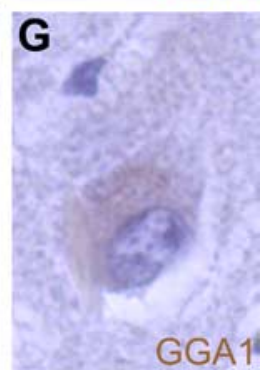

oculation of rabbits with synthetic $\mathrm{A} \beta 40$ and a peptide representing the last $15 \mathrm{C}$-terminal amino acids of human APP, respectively. Monoclonal antibodies 6E10 and 4G8 were obtained from Signet Laboratories (Dedham, MA). Polyclonal rabbit-antibody GGA1 was purchased from Abcam (Cambridge, UK). Monoclonal antibody Bapla, against the $\mathrm{A} \beta$ domain of APP, was described previously (Tamboli et al., 2005).

A fluorometric assay to determine BACE1 activity in cell lysates was obtained from R\&D Systems (Minneapolis, MN) and applied according to the supplier's instructions.

Human autopsy brains were received from the University Hospital Bonn, the Municipal Hospital Offenbach (Germany) and at the Huddinge Brain Bank in accordance with the laws and the permission of the local ethical committees. Clinical diagnosis was based on combined Diagnostic and Statistical Manual of Mental Disorders IV criteria. Additional information on brain material is detailed in supplemental Table 1 (available at www.jneurosci.org as supplemental material). Paraffin sections from different brain regions were studied by immunohistochemistry for GGA1. For neuropathological examination, paraffin sections were stained with the aldehyde fuchsin-Darrow red or hematoxylin and eosin, with the Gallyas silver method to detect neurofibrillary changes (Braak and Braak, 1991) and with an antibody raised against $\mathrm{A} \beta_{17-24}$ (4G8; 1:5000; formic acid pretreatment; Signet Laboratories) to stain senile plaques and cerebral amyloid angiopathy. The neuropathological diagnosis of definite $\mathrm{AD}$ was determined by using widely accepted consensus (The National Institute on Aging, and Reagan Institute Working Group on Diagnostic Criteria for the Neuropathological Assessment of Alzheimer's Disease, 1997). The stage of neurofibrillary pathology was determined according to Braak and Braak (1991); that for $\mathrm{A} \beta$ plaques and cerebral amyloid angiopathy was determined according to recently published criteria (Thal et al., 2002, 2003).

cDNAs, fusion proteins, and cell culture. The cDNAs encoding the human APP695 isoform, GGA1 full-length (FL) and dominant-negative (DN) have been described previously (Wahle et al., 2005). To generate fusion proteins of glutathione-S-transferase (GST), the different domains of GGA1 were amplified by PCR, and the resulting fragment was subcloned into EcoRI/SalI restriction sites of pGEX-5X-1 (GE Healthcare, Piscataway, NJ). Primer sequences used for PCR are available on request. Fusion proteins were expressed in Escherichia coli DH5 $\alpha$ and purified according to the supplier's instructions. Cloning of BACE CT fusion proteins was described previously (Walter et al., 2001b).

Human embryonic kidney (HEK) 293 and neuroblastoma SH-SY5Y cells were cultured in DMEM with Glutamax (Invitrogen, Carlsbad, CA) or RPMI (Roswell Park Memorial Institute) 1640 (Invitrogen) supplemented with $10 \%$ fetal calf serum, respectively. Cells were transfected with cDNAs encoding the APP695 isoform or the indicated GGA1 variants using fugene reagent (Roche, Indianapolis, IN), and stably expressing clones were selected by culturing in $200 \mu \mathrm{g} / \mathrm{ml} \mathrm{G} 418$ and $100 \mu \mathrm{g} / \mathrm{ml}$ Zeocin (Invitrogen), respectively. Cell viability was assessed by MTT [3-(4,5-dimethyl thiazol-2-yl)-2,5-diphenyl tetrazolium bromide] assay as described previously (Tamboli et al., 2005), and was not significantly affected during stable expression of GGA1 variants (data not shown).

RNA interference of GGA1 expression. For siRNA-mediated knockdown of GGA1, a mixture of three different siRNA oligonucleotides was used [Qiagen (Crawley, UK) siRNA hsGGA1_1, 1_3, 1_9]. Cells were 
transfected with 200 pM of each of the three siRNAs at 30\% confluency using Lipofectamine 2000 according to the manufacturer's instructions. As control, $600 \mathrm{pm}$ of nonsilencing siRNA was transfected (Qiagen). GGA1 knockdown was confirmed by Western immunoblotting using polyclonal GGA1 antibody (Abcam), as well as by real-time PCR (Bio-Rad, Hercules, CA) using specific probes. Expression of $\beta$-actin was analyzed as control.

Metabolic labeling and immunoprecipitation. Cells were starved at $37^{\circ} \mathrm{C}$ in methionine-free, serum-free medium for $45 \mathrm{~min}$ and then labeled with $\left[{ }^{35} \mathrm{~S}\right]$ methionine/ $\left[{ }^{35} \mathrm{~S}\right]$ cysteine (MP Biomedicals, Irvine, CA) at $37^{\circ} \mathrm{C}$ for the indicated time periods. Cells were then washed with PBS and chased in medium supplemented with $10 \%$ fetal calf serum and excess amount of unlabeled methionine as indicated in the respective experiments. After washing with PBS, cells were lysed in STEN buffer (in mM: 50 Tris, $\mathrm{pH}$ 7.6, $150 \mathrm{NaCl}$, and 2 EDTA) supplemented with $1 \%$ NP-40/1\% Triton X-100/2\% bovine serum albumin) on ice for $10 \mathrm{~min}$. Lysates were clarified by centrifugation for $20 \mathrm{~min}$ at $14000 \times g$.

Immunoprecipitation of the respective proteins from cleared lysates or conditioned media was performed at $4^{\circ} \mathrm{C}$ for $2 \mathrm{~h}$ with the antibodies indicated. Immunoprecipitated proteins were separated in SDS-PAGE, transferred to nitrocellulose membranes (Schleicher and Schuell BioScience, Keene, NH) and analyzed by autoradiography or phosphorimaging. Alternatively, proteins were detected by enhanced chemiluminescence technique (ECL reagent from GE Healthcare).

Immunocytochemistry and immunohistochemistry. Cells were grown on polylysinecoated glass coverslips to $50-80 \%$ confluence and fixed in $4 \%$ paraformaldehyde at room temperature before processing for immunofluorescence as described previously (Walter et al., $2001 b)$. Bound primary antibodies were detected by Alexa 488- or Alexa 594-conjugated secondary antibodies (Invitrogen). Cells were analyzed using a Nikon (Tokyo, Japan) fluorescence microscope (Eclipse E800) equipped with a digital camera, and micrographs were stored in tiff format and processed using the Photoshop program (Adobe Systems, San Jose, CA).

For immunohistochemistry, sections from human autopsy brain of the regions listed in supplemental Table 3 (available at www.jneurosci. org as supplemental material) were microtomed at $4 \mu \mathrm{m}$ thickness. Immunohistochemistry for the detection of GGAl was performed after pretreatment with $1 \mathrm{~N} \mathrm{HCl}$. Primary antibodies against GGAl were detected with biotinylated secondary antibodies directed against rabbitIgG, ABC complex, and 3,3 diaminobenzidine (DAB)- $\mathrm{HCl}$ (SigmaAldrich, St. Louis, MO). Counterstaining with hematoxylin was performed afterward. Sections were mounted in Corbit and viewed and documented with a Leica Microsystems (Wetzlar, Germany) DMLB microscope.

Double-label immunohistochemistry on control and AD brain sections was performed using the polyclonal anti-GGAl antibody combined with (1) an antibody raised against the CD68 epitope [CD68; Dako (Glostrup, Denmark); clone KP1; 1:100; protease pretreatment] detecting microglial cells and macrophages, (2) anti-A $\beta_{17-24}$, and (3) an antibody directed against abnormal phosphorylated $\tau$-protein (1:250; AT-8; Pierce-Endogen, Rockford, IL). The primary antibodies were visualized with carbocyanin 2 (Cy2)-labeled antibodies directed against mouse IgG and Cy3-labeled antibodies against rabbit IgG (1:50; Cy2 and Cy3; Di-
A

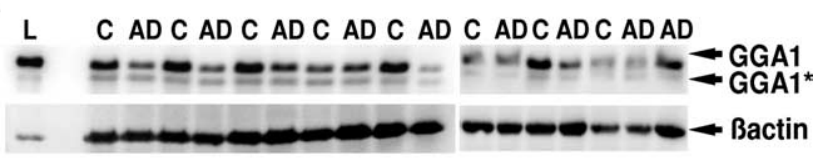

B

C $A D C A D C A D C A D C A D$

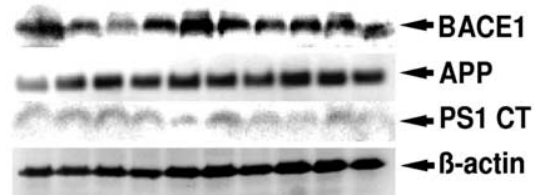

Figure 3. Decreased levels of GGA1 in human $\mathrm{AD}$ brain. $A$, Endogenous $\mathrm{GGA} 1$ in human brain lysates of $A D$ cases ( $A D$ ) and age-matched controls (C) was detected by Western immunoblotting. HEK293 cell lysate overexpressing a myc-tagged version of GGA1 was used as a positive control. L, Cell lysate. GGA1 is detected in two forms, likely representing phosphorylated (GGA1) and nonphosphorylated (GGA ${ }^{*}$ ) variants. $\beta$-Actin was used as a loading control. B, Detection of BACE1, APP, and PS1 in lysates of control and AD brains by Western blotting was performed as described in $\boldsymbol{A}$. 
anova, Hamburg, Germany). These sections were mounted in Corbit without counterstaining. Alternatively, double-label immunohistochemistry was performed with different chromogens. First, GGA1 was detected with biotinylated secondary antibodies directed against rabbit IgG and visualized with $\mathrm{ABC}$ complex and $\mathrm{DAB}$ (brown). For the second step, monoclonal mouse anti-GFAP or anti-A $\beta_{17-24}$ were administered to the sections after blocking peroxidase activity with methanol-hydrogen peroxide. The antibodies were detected with biotinylated secondary antibodies and visualized with the $\mathrm{ABC}$ complex and the Vector SGperoxidase kit (Vector Laboratories, Burlingame, CA). Immunolabeled sections were analyzed with the Leica Microsystems DMLB microscope.

Surface plasmon resonance measurements. Synthetic biotin-labeled peptides representing the cytoplasmic tail of APP or BACE1 were immobilized on a Biacore streptavidin chip using standard coupling according to the manufacturer's instructions. Binding curves for the respective fusion proteins (concentrations ranging from $50 \mathrm{~nm}$ to $5 \mu \mathrm{M}$ ) were obtained, and dissociation constants were determined by steady-state affinity curve fits.

Data analysis. For metabolic labeling experiments, band intensities were analyzed by phosphorimaging using FLA2000 (Fujifilm, Tokyo, Japan) and the Fujifilm Image Gauge 3.0 software. For enhanced chemiluminescence detection, signals were measured and analyzed using an ECL imager (ChemiDocTM XRS; Bio-Rad) and the Quantity One software package (Bio-Rad). For quantitations, three independent experiments $(n=3)$ were performed. Statistical analysis was performed using Student's $t$ test. Significance values are as follows: ${ }^{\star} p<0.05 ;{ }^{\star \star} P<0.01$. For brain material, exact logistic regression analysis controlled for age, gender, and Braak stage, and postmortem intervals were performed with LogXact 5.0 (Cytel, Cambridge, MA).

\section{Results}

Expression of GGA1 in human control and AD brain

Because the expression of GGA1 in the brain has not been characterized thus far, we first performed immunohistochemical experiments using human control and $\mathrm{AD}$ brains. In both $\mathrm{AD}$ and control brains, GGA1 was mainly located in the neuropil as well as in the perikaryon of the nerve cells (Fig. 1A) (supplemental Fig. 2, Table 3, available at www.jneurosci.org as supplemental material). Different types of nerve cells as well as different areas of the brain exhibited varying levels of GGA1. Within the neuropil, there is a mild to moderate diffuse staining (Fig. $1 A$ ), whereby the neuropil of the hippocampal formation was more strongly stained than the neuropil of the adjacent temporal neocortex (Fig. 1A). Similarly, the cytoplasmic expression of GGA1 in different neurons varied. Although dentate gyrus granule cells did not exhibit significant GGA1 reactivity, CA4 neurons were strongly positive and CA1/subiculum pyramidal cells showed a mild GGA1 immunodecoration (Fig. $1 B-G$ ). Microglial cells and oligodendrocytes contained no anti-GGA1-immunopositive material, whereas some astrocytes in the subpial zone of the molecular layer showed cytoplasmic GGA1 (supplemental Fig. 4, available at www.jneurosci.org as supplemental material). Overall, the neuronal expression pattern of GGAl did not show marked differences between control and AD brain (supplemental Fig. 2, supplemental Table 3, available at www.jneurosci.org as supplemental material). However, GGA1-positive astrocytes were seen more frequently in $\mathrm{AD}$ cases (Fig. 2A) (supplemental Fig. 4, available at www.jneurosci.org as supplemental material). They were found with and without association to senile plaques (Fig. 2A,B). GGA1-positive astrocytes were mainly found in neocortical and allocortical parts of the brain. Subcortical nuclei less frequently exhibited GGA1-positive astrocytes (supplemental Table 3, available at www.jneurosci.org as supplemental material). Amyloid material in senile plaques was not stained for GGA1 (Fig. 2C-F). In diffuse plaques, neurons embedded in the diffuse $\mathrm{A} \beta$-matrix faintly exhibited GGA1 (Fig. $2 C, D$ ). In cored
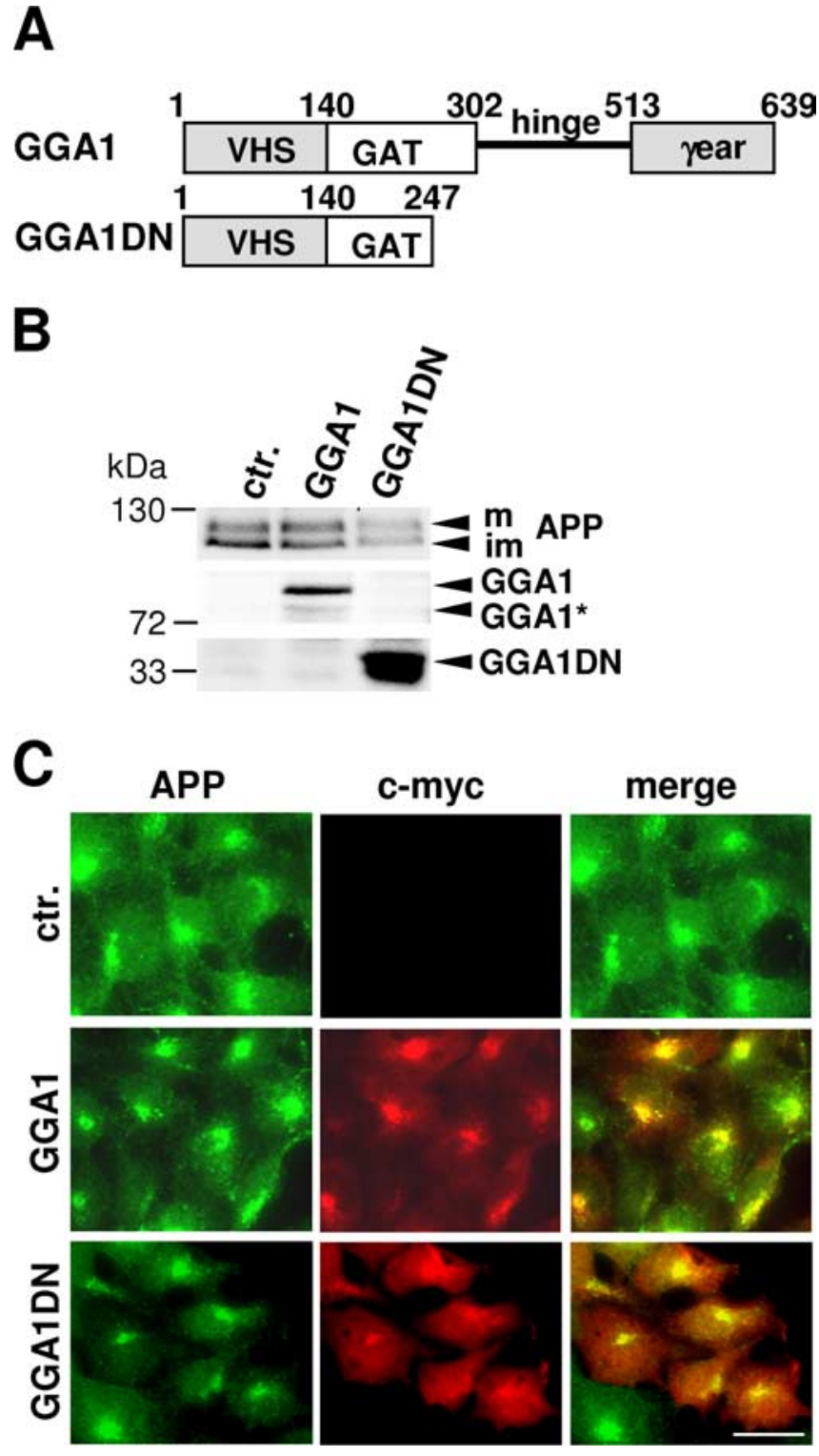

Figure 4. Colocalization of GGA1 and APP in cultured cells. $A$, Schematic of GGA1 including the VHS (amino acids 1-140), GAT (141-302), hinge (303-513) and $\gamma$-ear domain (514-639). GGA1 DN is truncated after amino acid 247 and lacks parts of the GAT domain as well as the hinge and $\gamma$-ear domains. $\boldsymbol{B}$, Stable expression of APP and c-myc-tagged GGA1 variants in HEK293 cells. Protein-matched samples were loaded on SDS-PAGE, and the expression pattern was analyzed by Western immunoblotting with antibodies against the cytoplasmic domain of APP (140) and c-myc, respectively. APP is expressed in its mature ( $\mathrm{m}$ ) and immature (im) form. GGA1 is present in two forms, which might represent the phosphorylated and nonphosphorylated $\left(^{*}\right)$ species. C, Subcellular localization of APP and GGA1 variants was analyzed by costaining with polyclonal antibody 140 and monoclonal anti-c-myc antibody. Primary antibodies were detected by Alexa 488-conjugated anti-rabbit (green) and Alexa 594-conjugated anti-mouse secondary antibodies (red), respectively. Scale bar, $20 \mu \mathrm{m}$. ctr., Cells expressing APP alone.

plaques, activated microglial cells, bordering the amyloid core, exhibited GGA1 as demonstrated by the colocalization of the microglial-associated epitope CD68 and GGA1 and by demonstrating GGA1-positive cells being associated with cored plaques in an anti-GGA1-anti-A $\beta_{17-24}$ double labeling (Fig. $2 G-I$ ). In addition, microglial cells bordering $A \beta$ plaques were also seen (Fig. 2E). Double labeling of GGA1 and abnormal $\tau$-protein showed that neurons that accumulate abnormal $\tau$-protein do not differ in the exhibition of GGA1 from neighboring neurons negative for abnormal $\tau$-protein (Fig. $2 J-L$ ). 
We next analyzed the expression levels of GGA1 in brains of AD cases and controls by Western immunoblotting. Consistent with results from cultured cells (Ghosh and Kornfeld, 2003), two variants of GGA1 were also detected in human brain lysates that might represent phosphorylated and nonphosphorylated forms. Interestingly, levels of GGA1 were found to be significantly decreased in $\mathrm{AD}$ brains by $\sim 40 \%(p<0.05)$ (Fig. $3 A$ ). Consistent with previous data (Holsinger et al., 2002; Yang et al., 2003; Sastre et al., 2006), levels of BACE1 were slightly increased in $\mathrm{AD}$ brains (Fig. $3 B$ ). Levels of presenilin 1, a critical component of the $\gamma$-secretase complex, and that of APP were not significantly changed (Fig. $3 B$ ).

\section{Colocalization of GGA1 and APP in cultured cells}

To investigate the functional role of GGA1 proteins in the proteolytic processing of APP, we first used HEK293 cells that endogenously express $\beta$-secretase activity (Haass et al., 1992; Vassar et al., 1999). These cells were stably transfected with cDNA of human APP695 alone or in combination with myc-tagged GGA1 FL or DN variant that includes the VHS and a part of the GAT domain, responsible for binding to cargo proteins and ARF, respectively (Fig. 4A). The GGA1 DN variant has been shown to interfere with transport of cargo protein from TGN to endosomal/lysosomal compartments (Puertollano et al., 2001). Western immunoblotting demonstrated the stable expression of APP and the respective GGA1 variants (Fig. $4 B$ ). Immunocytochemical experiments revealed localization of APP predominantly in juxtanuclear and peripheral vesicular structures, where it colocalizes with both GGA1 FL and GGA1 DN variants (Fig. $4 C)$. To characterize these structures, cells were costained with antibodies against TGN46 and early endosomal antigen 1 (EEA1) that localize the TGN and early endosomal compartments, respectively. Consistent with a localization of APP in the TGN and early endosomes, APP partly colocalized with TGN46 and EEA1, respectively (Fig. $5 A, B$ ). The expression of GGA1 variants had no apparent effects on the localization of APP in the TGN and endosomes (Fig. 5A,B), indicating that GGA1 did not affect subcellular trafficking of APP. As revealed by pulse-chase experiments, the maturation of APP was also unaltered by the overexpression of GGA1 variants (Fig. $5 C$ ), indicating that the transport of APP from the endoplasmic reticulum to and within the Golgi compartment was not affected by GGA1. Moreover, biotinylation experiments revealed that APP

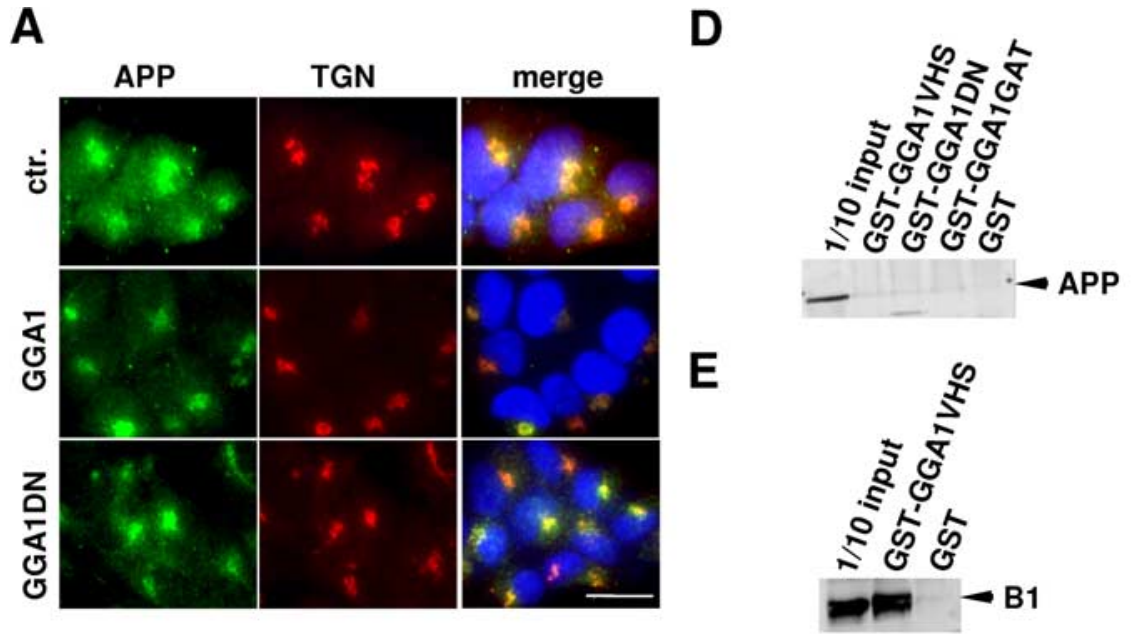

B

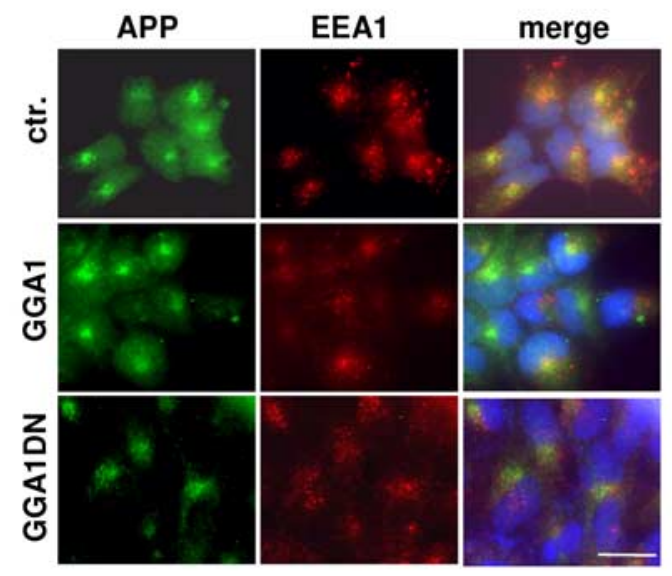

$\mathbf{F}$

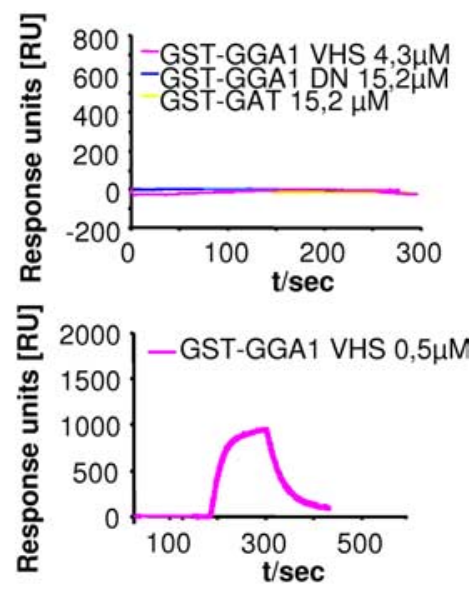

Figure 5. Analysis of the subcellular localization of APP and its interaction with GGA1.A, B, Localization of APP to the TGN and endosomal compartments by fluorescence microscopy. Cells stably expressing APP alone (ctr.), or together with GGA1 or GGA1 DN were stained with polyclonal antibodies against APP. Cells were costained with monoclonal antibodies against TGN46 (A) or EEA1 (B). Primary antibodies were detected by Alexa 488-conjugated anti-rabbit (green) and Alexa 594-conjugated anti-mouse secondary antibodies (red), respectively. Nuclei were stained with DAPI. Scale bar, $20 \mu \mathrm{m}$. C, Maturation of APP. HEK293 cells expressing APP alone or together with GGA1 or GGA1 DN were pulse labeled with [ ${ }^{35}$ S] methionine for 15 min and chased for the indicated time periods. Cells were lysed, and APP was immunoprecipitated with antibody 140 . Radiolabeled proteins were detected by phosphorimaging. Mature (m) and immature (im) forms of APP are indicated. $\boldsymbol{D}$, Interaction of GGA1 and APP was investigated by pull-down assays. Lysates of HEK293 cells overexpressing APP were incubated with GST fusion proteins carrying the VHS (GST-GGA1VHS), VHS plus GAT (GST-GGA1 DN), or the GAT (GST-GGA1GAT) domain. GST was used as a negative control. Precipitated APP was detected by Western immunoblotting with antibody 140.E, Lysates of HEK293 cells overexpressing BACE1 were incubated with the fusion protein GST-GGA1VHS or GST alone. Precipitated BACE1 was detected by Western immunoblotting. Although BACE1 was precipitated with GSTGGA1VHS (D), no significant interaction of APP was detected with the different fusion proteins $(\boldsymbol{E})$. $\boldsymbol{F}$, Surface plasmon resonance analysis of the interaction of APP or BACE1 with GST fusion proteins. APP (top) or BACE1 (bottom) C-terminal peptides were immobilized on sensor chips, and the respective GST-GGA1 fusion proteins were injected at the indicated concentrations.

expression at the cell surface is not significantly changed during expression of GGA1 FL or DN variants (data not shown).

To assess whether APP directly binds to GGA1, we first performed pull-down assays with GST fusion proteins that carry 
distinct functional domains of GGA1. However, no significant binding between GGA1 and APP was observed (Fig. 5D). In addition, we also applied surface plasmon resonance spectrometry to test a potential interaction of the APP cytoplasmic domain with GGA1. Consistent with the results from pull-down assays, no binding of APP to GGA1 was detected by both methods, whereas the cytoplasmic domain of BACE1 readily bound to GGA1 under similar conditions (Fig. $5 F$ ). Together, these data indicate that GGA1 colocalizes with, but does not directly bind to, APP.

\section{GGA1 affects proteolytic processing of APP}

Because recent data demonstrate that GGAs alter endocytic trafficking of BACE1 (Wahle et al., 2005), we next analyzed whether overexpression of GGA1 variants affect proteolytic processing of APP by pulse-chase experiments. Cells were radiolabeled with $\left[{ }^{35} \mathrm{~S}\right]$ methionine and APP, and its proteolytic processing derivatives were immunoprecipitated from cell lysates and conditioned media with antibodies directed against APP intracellular and extracellular domains, respectively. Although overexpression of GGA1 FL did not significantly alter the secretion of total APPs, cells overexpressing GGA1 DN secreted significantly lower levels of APPs (Fig. 6A, $B$ ). To specifically detect APPs- $\alpha$, media were also immunoprecipitated with an antibody against the $\mathrm{A} \beta$ domain. Consistent with previous studies (Haass et al., 1992; Tamboli et al., 2005), HEK293 cells predominantly secrete APPs- $\alpha$ compared with APPs- $\beta$, indicating relative low $\beta$-secretase activity in this cell type (data not shown). In cells expressing GGA1 $\mathrm{DN}$, secretion of APPs- $\alpha$ was also markedly reduced, whereas GGA1 FL expression did not significantly affect APPs- $\alpha$ secretion compared with cells overexpressing APP alone (Fig. 6A,C). Neither GGA1 FL nor GGA1 DN affected total protein secretion, indicating a selective effect on secretion and/or proteolytic processing of APP (supplemental Fig. 5, available at www.jneurosci. org as supplemental material).

Notably, the expression of both GGA1 FL and GGA1 DN led to marked reduction in $\mathrm{A} \beta$ secretion (Fig. $6 A, E$ ). Very similar effects were also observed with the human neuroblastoma cell line SH-SY5Y (Fig. $6 F$ ). Because the secretion of $\mathrm{A} \beta$ is affected by the relative contribution of $\alpha$ - and $\beta$-secretase to the processing of APP, which results in generation of CTF- $\alpha$ and CTF- $\beta$, respectively, we also analyzed the levels of APP CTF variants in the different cell lines. Compared with cells overexpressing APP alone, cells coexpressing GGA1 FL or GGA1 DN revealed decreased levels of CTF- $\beta$ (Fig. $6 A, D$ ), suggesting decreased cleavage of APP by $\beta$-secretase relative to cleavage by $\alpha$-secretase. Because neither the maturation nor total cellular activity of BACE1 is altered by GGA1 expression (supplemental Fig. 5, available at www.jneurosci.org as supplemental material), these data suggest that altered subcellular trafficking of BACE1 contributed to differences in $\beta$-secretory processing of APP and secretion of $\mathrm{A} \beta$. This notion is also supported by the finding that expression of GGA1 FL or DN variants did not affect the levels of AICD (APP intracellular domain), indicating unaltered cellular $\gamma$-secretase activity (supplemental Fig. 5, available at www.jneurosci.org as supplemental material).

We also used an RNAi approach to decrease endogenous GGA1 expression. H4 cells were transfected with specific siRNA oligonucleotides targeting human GGA1 mRNA or with nontargeting control oligonucleotides. The cells transfected with GGA1 siRNAs showed decreased expression of endogenous GGA1 protein compared with control cells (Fig. $6 G$ ). As determined by real time reverse transcription-PCR, GGA1 mRNA levels were also

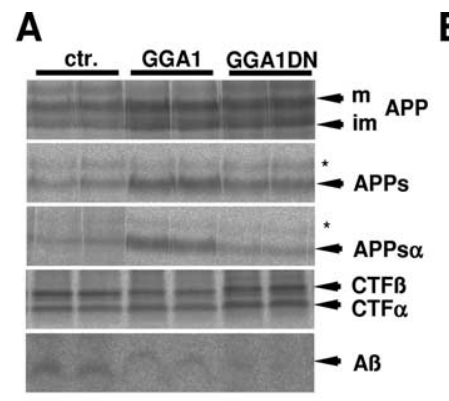

B
C

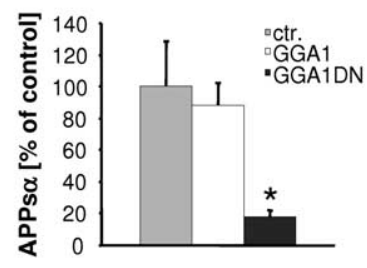

E

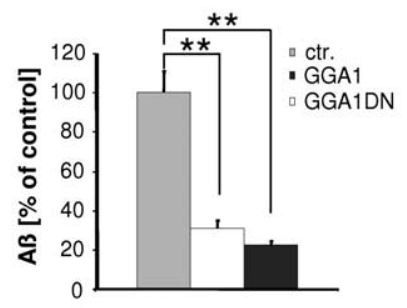

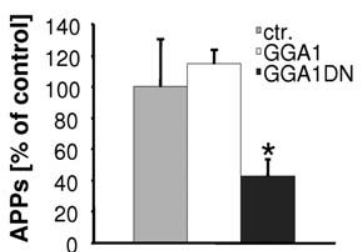

D

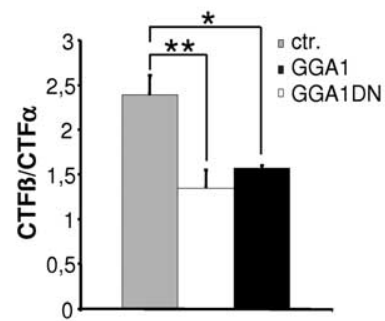

$\mathbf{F}$
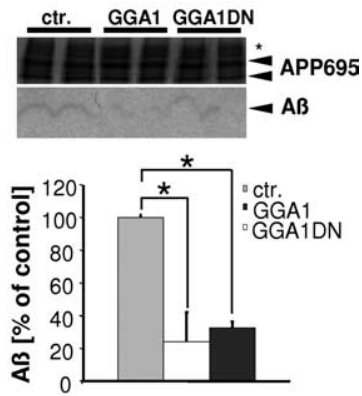

$\mathbf{G}$

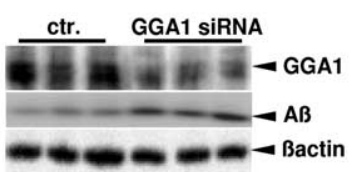

Figure 6. GGA1 affects the proteolytic processing of APP and decreases secretion of A $\beta$. A, HEK293 cells expressing APP alone (ctr) or together with GGA1 or GGA1 DN were pulse labeled with [ ${ }^{35} \mathrm{~S}$ ]methionine for $2 \mathrm{~h}$. One set of cells was immediately lysed after the pulse, and APP was immunoprecipitated from the cell lysates (top row). Another set of cells was chased for $6 \mathrm{~h}$, and secreted APP was immunoprecipitated with antibody 5313 that recognizes both APPs- $\alpha$ and APPs- $\beta$ (second row), or immunoprecipitated with antibody BAP1a that selectively detects APPs- $\alpha$ (third row). Radiolabeled proteins were detected by phosphorimaging. APP CTFs were immunoprecipitated with antibody 140 from cell lysates, and $A \beta$ was immunoprecipitated with antibody 2964 from the chase media. Precipitates were separated by SDS-PAGE, and radiolabeled proteins were detected by phosphoimaging. $B, C$, Quantification of secreted total APPs $(\boldsymbol{B})$ and APPs- $\alpha(\boldsymbol{C})$ by normalization to total cellular APP after pulse labeling. $\boldsymbol{D}, \boldsymbol{E}$, Quantification of $A \beta$ secretion $(\boldsymbol{E})$ and cellular levels of CTF- $\alpha$ and CTF- $\beta$ (D) by phosphoimaging. Values represent means of three independent experiments $\pm S D$. $F$, GGA1 expression and $A \beta$ generation in neuroblastoma cells. SH-SY5Y cells were transiently transfected with APP alone or together with GGA1 or GGA1 DN. Pulse-chase experiment and analysis of $A \beta$ secretion was performed as described above by phosphoimaging (top row) and quantification (bottom row). G, H4 cells were transfected with nontargeting (ctr.) or GGA1-specific siRNAs. Expression of endogenous GGA1 in cell lysates was analyzed by Western immunoblotting (top). Secreted $A \beta$ was immunoprecipitated with antibody 2964 and detected with by Western immunoblotting with monoclonal antibody 6 E10. $\beta$-actin in cell lysates was detected as control.

decreased by $74 \%$ (data not shown). The RNAi-mediated suppression of GGA1 significantly increased levels of secreted $A \beta$ of $\sim 30 \%$ ( $p<0.05$ ) compared with control cells, also supporting a role of GGA1 in the proteolytic processing of APP (Fig. $6 G$ ). 


\section{Discussion}

The role of GGA proteins in the nervous system is not known. GGAl mRNA has been detected in brain tissue (Boman et al., 2000), but expression of the corresponding protein has not been demonstrated thus far. We show by immunohistochemical experiments that GGA1 mainly occurred in the neuropil and in the cytoplasm of neurons in both control and $\mathrm{AD}$ brains. The expression of GGA1 varied in different types of neurons, but did not show significant differences between control and $\mathrm{AD}$ brain as well as between neurofibrillary tangle-bearing neurons and neurofibrillary tangle-free neurons in $\mathrm{AD}$ cases. However, the number of GGA1positive astrocytes was higher in $\mathrm{AD}$ cases compared with controls. Interestingly, senile plaque-associated microglial cells also express GGA1, whereas the amyloid material itself did not stain positive for GGA1. Thus, reactive plaque-associated microglial cells appear to upregulate GGA1 in the pathogenesis of $\mathrm{AD}$. By quantitative Western immunoblotting, we detected decreased GGA1 expression in AD brains as compared with controls, whereas BACE1 levels are slightly increased. However, the physiological relevance of decreased GGA1 expression on APP processing and $\mathrm{A} \beta$ generation is unclear in the absence of GGA1 knock-out mice.

For functional investigations on the role of GGA proteins on proteolytic processing of APP, we used mainly HEK293 cells that endogenously express low levels of $\beta$-secretase activity and have been used to identify BACE1 (Sinha et al., 1999; Vassar et al., 1999; Yan et al., 1999). Our immunocytochemical studies revealed that GGA1 colocalized with APP in juxtanuclear and peripheral vesicular structures, indicating localization of both proteins in Golgi and endosomal compartments. However, we did not detect a direct interaction of these proteins by pull-down assays or surface plasmon resonance analysis. This is consistent with the lack of a DXXLL motif in the cytoplasmic domain of APP that determines recognition by the VHS domain of GGA proteins. Therefore, it is unlikely that APP represents a cargo protein of GGAs and that its subcellular trafficking is regulated by direct binding to GGAs.

GGA proteins have been shown to interact with the cytoplasmic domain of BACE1 in a phosphorylation-state-dependent manner and to regulate the endocytic trafficking of this protease (He et al., 2002, 2003, 2005; von Arnim et al., 2004; Wahle et al., 2005). It was therefore speculated that phosphorylation of BACE1 and/or interaction with GGAs is also implicated in the $\beta$-secretory processing of APP and the generation of A $\beta$. However, in previous studies, no significant differences in APP processing were observed in cells that overexpressed BACE1 (von Arnim et al., 2004; He et al., 2005). This might be partly attributable to aberrant cleavage of APP by overexpressed BACE1. Indeed, it has been shown that overexpression of BACE1 strongly increases $\beta$-secretory cleavage of APP already in early secretory compartments (Capell et al., 2000; Liu et al., 2002; Lee et al., 2005), whereas under physiological expression levels, $\beta$-secretase cleavage of wild-type APP has been localized predominantly to endosomal/lysosomal compartments (Koo and Squazzo, 1994; Haass et al., 1995; Thinakaran et al., 1996). High overexpression of BACE1 was also shown to decrease $A \beta$ levels in cell culture and transgenic mice by additional cleavages within $\mathrm{A} \beta$ (Fluhrer et al., 2002, 2003; Liu et al., 2002; Lee et al., 2005). Thus, overexpression of BACE1 and aberrant cleavage of APP might have masked GGA-dependent effects on post-Golgi secretory and endocytic trafficking.

The expression of a GGA1 DN variant in HEK293 cells with endogenous BACE1 expression resulted in decreased secretion of APP variants, whereas GGA1 FL did not significantly affect APP secretion. Importantly, $A \beta$ secretion was significantly reduced by overexpressing GGA1 FL or the DN variant in both peripheral (HEK293) and neuroblastoma (SH-SY5Y) cell lines. In addition, suppression of GGA1 expression by RNAi resulted in an increased $\mathrm{A} \beta$ secretion. Which mechanisms could underlie the observed changes in the secretion of APPs and A $\beta$ ? BACE1 and APP share similar transport routes from the Golgi to the cell surface (Fig. 7). Although most of the APP is cleaved in this pathway by $\alpha$-secretase, at least in HEK293 cells, $\beta$-secretase activity has been demonstrated in the TGN and secretory vesicles that contribute to increased $\beta$-cleavage of Swedish mutant APP and increased A $\beta$ secretion (Haass et al., 1995; Thinakaran et al., 1996). From the cell surface, both APP and BACE1 could be internalized into endosomal compartments, in which APP could preferentially be cleaved by $\beta$-secretase. Because GGA1 could shuttle BACE1 from endosomal compartments to other compartments, including the TGN, this could reduce the amount of BACE1 in endosomes and thus $\beta$-secretory cleavage of APP. In line with this, decreasing expression of GGA1 by RNAi led to elevated secretion of $A \beta$, probably by increasing the amount of BACE1 in endosomal compartments. GGA proteins could also facilitate transport of specific cargo proteins [e.g., the mannose 6 phosphate receptors (M6PRs)] from the TGN to endosomal compartments and the expression of GGA1 DN inhibits this transport route (Puertollano et al., 2001; Zhu et al., 2001). We detected colocalization and 
copurification of BACE1 with AP-1-positive vesicles (data not shown), known to mediate the direct transport of cargo proteins from TGN to endosomes (Diaz and Pfeffer, 1998; Meyer et al., 2000). Therefore, BACE1 might also undergo direct transport from TGN to endosomal/lysosomal compartments without passing the cell surface (Fig. 7). In that case, expression of GGA1 DN might lead to reduced BACE1 levels in endosomal/lysosomal compartments and thereby decrease $\beta$-secretory processing of $\mathrm{APP}$ and $\mathrm{A} \beta$ generation in this compartment.

GGA proteins could also affect the proteolytic processing of APP, independent of a direct interaction with BACE1. It was demonstrated that LR11/SorLA interacts with APP and affects its subcellular localization and proteolytic processing (Andersen et al., 2006; Offe et al., 2006; Spoelgen et al., 2006). Because LR11/ sorLA also represents a cargo for GGA proteins (Jacobsen et al., 2002), it is plausible that trafficking and metabolism of APP could be affected when LR11/SorLA is complexed with GGA proteins. In addition, GGA proteins are adaptor proteins that, in addition to binding to cargo proteins, also interact with the small GTPase ARF, clathrin, and additional proteins involved in vesicle assembly and targeting (Bonifacino, 2004). Therefore, expression of GGA1 variants might also impair vesicular transport by interfering with ARF- or clathrin-dependent mechanisms that could also alter APP processing. In addition, GGAs could also affect APP metabolism indirectly by regulating the transport of other proteins. Indeed, GGAs also mediate forward trafficking of the M6PR from the TGN to endosomal compartments (Puertollano et al., 2001), and expression of this receptor has also been shown to affect $\mathrm{A} \beta$ generation (Mathews et al., 2002). Thus, GGAdependent changes in M6PR trafficking could also contribute to the observed changes in APP processing. It will be interesting to further dissect the GGA-dependent mechanisms that regulate the proteolytic processing of APP and thereby determine their potential role in the pathogenesis of $\mathrm{AD}$.

\section{References}

Aguzzi A, Haass C (2003) Games played by rogue proteins in prion disorders and Alzheimer's disease. Science 302:814-818.

Andersen OM, Schmidt V, Spoelgen R, Gliemann J, Behlke J, Galatis D, McKinstry WJ, Parker MW, Masters CL, Hyman BT, Cappai R, Willnow TE (2006) Molecular dissection of the interaction between amyloid precursor protein and its neuronal trafficking receptor SorLA/LR11. Biochemistry 45:2618-2628.

Annaert W, de Strooper B (2002) A cell biological perspective on Alzheimer's disease. Annu Rev Cell Dev Biol 18:25-51.

Boman AL, Zhang C, Zhu X, Kahn RA (2000) A family of ADP-ribosylation factor effectors that can alter membrane transport through the transGolgi. Mol Biol Cell 11:1241-1255.

Bonifacino JS (2004) The GGA proteins: adaptors on the move. Nat Rev Mol Cell Biol 5:23-32.

Braak H, Braak E (1991) Neuropathological stageing of Alzheimer-related changes. Acta Neuropathol (Berl) 82:239-259.

Capell A, Steiner H, Willem M, Kaiser H, Meyer C, Walter J, Lammich S, Multhaup G, Haass C (2000) Maturation and pro-peptide cleavage of beta-secretase. J Biol Chem 275:30849-30854.

Creemers JW, Dominguez DI, Plets E, Serneels L, Taylor NA, Multhaup G, Craessaerts K, Annaert W, de Strooper B (2000) Processing of betasecretase (Bace) by furin and other members of the proprotein convertase family. J Biol Chem 8:8.

Dell'Angelica EC, Puertollano R, Mullins C, Aguilar RC, Vargas JD, Hartnell LM, Bonifacino JS (2000) GGAs: a family of ADP ribosylation factorbinding proteins related to adaptors and associated with the Golgi complex. J Cell Biol 149:81-94.

Diaz E, Pfeffer SR (1998) TIP47: a cargo selection device for mannose 6-phosphate receptor trafficking. Cell 93:433-443.

Doray B, Ghosh P, Griffith J, Geuze HJ, Kornfeld S (2002) Cooperation of
GGAs and AP-1 in packaging MPRs at the trans-Golgi network. Science 297:1700-1703.

Fluhrer R, Capell A, Westmeyer G, Willem M, Hartung B, Condron MM, Teplow DB, Haass C, Walter J (2002) A non-amyloidogenic function of BACE-2 in the secretory pathway. J Neurochem 81:1011-1020.

Fluhrer R, Multhaup G, Schlicksupp A, Okochi M, Takeda M, Lammich S, Willem M, Westmeyer G, Bode W, Walter J, Haass C (2003) Identification of a beta-secretase activity, which truncates amyloid beta-peptide after its presenilin-dependent generation. J Biol Chem 278:5531-5538.

Ghosh P, Kornfeld S (2003) Phosphorylation-induced conformational changes regulate GGAs 1 and 3 function at the trans-Golgi network. J Biol Chem 278:14543-14549.

Haass C, Schlossmacher MG, Hung AY, Vigo-Pelfrey C, Mellon A, Ostaszewski BL, Lieberburg I, Koo EH, Schenk D, Teplow DB, Selkoe DJ (1992) Amyloid beta-peptide is produced by cultured cells during normal metabolism. Nature 359:322-325.

Haass C, Lemere CA, Capell A, Citron M, Seubert P, Schenk D, Lannfelt L, Selkoe DJ (1995) The Swedish mutation causes early-onset Alzheimer's disease by beta- secretase cleavage within the secretory pathway. Nat Med 1:1291-1296.

Haniu M, Denis P, Young Y, Mendiaz EA, Fuller J, Hui JO, Bennett BD, Kahn S, Ross S, Burgess T, Katta V, Rogers G, Vassar R, Citron M (2000) Characterization of Alzheimer's beta-secretase protein BACE. A pepsin family member with unusual properties. J Biol Chem 275:21099-21106.

Hardy J, Selkoe DJ (2002) The amyloid hypothesis of Alzheimer's disease: progress and problems on the road to therapeutics. Science 297:353-356.

He X, Chang WP, Koelsch G, Tang J (2002) Memapsin 2 (beta-secretase) cytosolic domain binds to the VHS domains of GGA1 and GGA2: implications on the endocytosis mechanism of memapsin 2. FEBS Lett 524:183-187.

He X, Zhu G, Koelsch G, Rodgers KK, Zhang XC, Tang J (2003) Biochemical and structural characterization of the interaction of memapsin 2 (betasecretase) cytosolic domain with the VHS domain of GGA proteins. Biochemistry 42:12174-12180.

He X, Li F, Chang WP, Tang J (2005) GGA proteins mediate the recycling pathway of memapsin 2 (BACE). J Biol Chem 280:11696-11703.

Hirst J, Lui WW, Bright NA, Totty N, Seaman MN, Robinson MS (2000) A family of proteins with gamma-adaptin and VHS domains that facilitate trafficking between the trans-Golgi network and the vacuole/lysosome. J Cell Biol 149:67-80.

Holsinger RM, McLean CA, Beyreuther K, Masters CL, Evin G (2002) Increased expression of the amyloid precursor beta-secretase in Alzheimer's disease. Ann Neurol 51:783-786.

Huse JT, Pijak DS, Leslie GJ, Lee VM, Doms RW (2000) Maturation and endosomal targeting of beta-site amyloid precursor protein-cleaving enzyme. The Alzheimer's disease beta-secretase. J Biol Chem 275:33729-33737.

Hussain I, Powell D, Howlett DR, Tew DG, Meek TD, Chapman C, Gloger IS, Murphy KE, Southan CD, Ryan DM, Smith TS, Simmons DL, Walsh FS, Dingwall C, Christie G (1999) Identification of a novel aspartic protease (Asp 2) as beta-secretase. Mol Cell Neurosci 14:419-427.

Jacobsen L, Madsen P, Nielsen MS, Geraerts WP, Gliemann J, Smit AB, Petersen CM (2002) The sorLA cytoplasmic domain interacts with GGA1 and -2 and defines minimum requirements for GGA binding. FEBS Lett 511:155-158.

Koo EH, Squazzo SL (1994) Evidence that production and release of amyloid beta-protein involves the endocytic pathway. J Biol Chem 269:17386-17389.

Lee EB, Zhang B, Liu K, Greenbaum EA, Doms RW, Trojanowski JQ, Lee VM (2005) BACE overexpression alters the subcellular processing of APP and inhibits Abeta deposition in vivo. J Cell Biol 168:291-302.

Lin X, Koelsch G, Wu S, Downs D, Dashti A, Tang J (2000) Human aspartic protease memapsin 2 cleaves the beta-secretase site of beta-amyloid precursor protein. Proc Natl Acad Sci USA 97:1456-1460.

Liu K, Doms RW, Lee VM (2002) Glu11 site cleavage and N-terminally truncated abeta production upon BACE overexpression. Biochemistry 41:3128-3136.

Mathews PM, Guerra CB, Jiang Y, Grbovic OM, Kao BH, Schmidt SD, Dinakar R, Mercken M, Hille-Rehfeld A, Rohrer J, Mehta P, Cataldo AM, Nixon RA (2002) Alzheimer's disease-related overexpression of the cation-dependent mannose 6-phosphate receptor increases Abeta secre- 
tion: role for altered lysosomal hydrolase distribution in betaamyloidogenesis. J Biol Chem 277:5299-5307.

Meyer C, Zizioli D, Lausmann S, Eskelinen EL, Hamann J, Saftig P, Von Figura K, Schu P (2000) mulA-adaptin-deficient mice: lethality, loss of AP-1 binding and rerouting of mannose 6-phosphate receptors. EMBO J 19:2193-2203.

Offe K, Dodson SE, Shoemaker JT, Fritz JJ, Gearing M, Levey AI, Lah JJ (2006) The lipoprotein receptor LR11 regulates amyloid beta production and amyloid precursor protein traffic in endosomal compartments. J Neurosci 26:1596-1603.

Pastorino L, Ikin AF, Nairn AC, Pursnani A, Buxbaum JD (2002) The carboxyl-terminus of BACE contains a sorting signal that regulates BACE trafficking but not the formation of total A(beta). Mol Cell Neurosci 19:175-185.

Puertollano R, Aguilar RC, Gorshkova I, Crouch RJ, Bonifacino JS (2001) Sorting of mannose 6-phosphate receptors mediated by the GGAs. Science 292:1712-1716.

Sastre M, Dewachter I, Rossner S, Bogdanovic N, Rosen E, Borghgraef P, Evert BO, Dumitrescu-Ozimek L, Thal DR, Landreth G, Walter J, Klockgether T, Van Leuven F, Heneka MT (2006) Nonsteroidal antiinflammatory drugs repress beta-secretase gene promoter activity by the activation of PPARgamma. Proc Natl Acad Sci USA 103:443-448.

Selkoe DJ (2001) Alzheimer's disease: genes, proteins, and therapy. Physiol Rev 81:741-766.

Shiba T, Kametaka S, Kawasaki M, Shibata M, Waguri S, Uchiyama Y, Wakatsuki S (2004) Insights into the phosphoregulation of beta-secretase sorting signal by the VHS domain of GGA1. Traffic 5:437-448.

Sinha S, Anderson JP, Barbour R, Basi GS, Caccavello R, Davis D, Doan M, Dovey HF, Frigon N, Hong J, Jacobson-Croak K, Jewett N, Keim P, Knops J, Lieberburg I, Power M, Tan H, Tatsuno G, Tung J, Schenk D, Seubert P, Suomensaari SM, Wang S, Walker D, John V, et al (1999) Purification and cloning of amyloid precursor protein beta-secretase from human brain. Nature 402:537-540.

Spoelgen R, von Arnim CA, Thomas AV, Peltan ID, Koker M, Deng A, Irizarry MC, Andersen OM, Willnow TE, Hyman BT (2006) Interaction of the cytosolic domains of sorLA/LR11 with the amyloid precursor protein (APP) and beta-secretase beta-site APP-cleaving enzyme. J Neurosci 26:418-428.

Tamboli IY, Prager K, Barth E, Heneka M, Sandhoff K, Walter J (2005) Inhibition of glycosphingolipid biosynthesis reduces secretion of the beta-amyloid precursor protein and amyloid beta-peptide. J Biol Chem 280:28110-28117.

Thal DR, Rub U, Orantes M, Braak H (2002) Phases of A beta-deposition in the human brain and its relevance for the development of AD. Neurology 58:1791-1800.
Thal DR, Ghebremedhin E, Orantes M, Wiestler OD (2003) Vascular pathology in Alzheimer disease: correlation of cerebral amyloid angiopathy and arteriosclerosis/lipohyalinosis with cognitive decline. J Neuropathol Exp Neurol 62:1287-1301.

The National Institute on Aging, and Reagan Institute Working Group on Diagnostic Criteria for the Neuropathological Assessment of Alzheimer's Disease (1997) Consensus recommendations for the postmortem diagnosis of Alzheimer's disease. Neurobiol Aging 18:S1-S2.

Thinakaran G, Teplow DB, Siman R, Greenberg B, Sisodia SS (1996) Metabolism of the "Swedish" amyloid precursor protein variant in neuro2a (N2a) cells. Evidence that cleavage at the "beta-secretase" site occurs in the Golgi apparatus. J Biol Chem 271:9390-9397.

Vassar R, Citron M (2000) Abeta-generating enzymes: recent advances in beta- and gamma-secretase research. Neuron 27:419-422.

Vassar R, Bennett BD, Babu-Khan S, Kahn S, Mendiaz EA, Denis P, Teplow DB, Ross S, Amarante P, Loeloff R, Luo Y, Fisher S, Fuller J, Edenson S, Lile J, Jarosinski MA, Biere AL, Curran E, Burgess T, Louis JC, et al. (1999) Beta-secretase cleavage of Alzheimer's amyloid precursor protein by the transmembrane aspartic protease BACE. Science 286:735-741.

von Arnim CA, Tangredi MM, Peltan ID, Lee BM, Irizarry MC, Kinoshita A, Hyman BT (2004) Demonstration of BACE (\{beta\}-secretase) phosphorylation and its interaction with GGAl in cells by fluorescencelifetime imaging microscopy. J Cell Sci 117:5437-5445.

Wahle T, Prager K, Raffler N, Haass C, Famulok M, Walter J (2005) GGA proteins regulate retrograde transport of BACE1 from endosomes to the trans-Golgi network. Mol Cell Neurosci 29:453-461.

Walter J, Kaether C, Steiner H, Haass C (2001a) The cell biology of Alzheimer's disease: uncovering the secrets of secretases. Curr Opin Neurobiol 11:585-690.

Walter J, Fluhrer R, Hartung B, Willem M, Kaether C, Capell A, Lammich S, Multhaup G, Haass C (2001b) Phosphorylation regulates intracellular trafficking of beta-secretase. J Biol Chem 276:14634-14641.

Yan R, Bienkowski MJ, Shuck ME, Miao H, Tory MC, Pauley AM, Brashier JR, Stratman NC, Mathews WR, Buhl AE, Carter DB, Tomasselli AG, Parodi LA, Heinrikson RL, Gurney ME (1999) Membrane-anchored aspartyl protease with Alzheimer's disease beta- secretase activity. Nature 402:533-537.

Yang LB, Lindholm K, Yan R, Citron M, Xia W, Yang XL, Beach T, Sue L, Wong P, Price D, Li R, Shen Y (2003) Elevated beta-secretase expression and enzymatic activity detected in sporadic Alzheimer disease. Nat Med 9:3-4.

Zhu Y, Doray B, Poussu A, Lehto VP, Kornfeld S (2001) Binding of GGA2 to the lysosomal enzyme sorting motif of the mannose 6-phosphate receptor. Science 292:1716-1718. 